\title{
Pengendalian Kualitas Air untuk Tanaman Hidroponik Menggunakan Raspberry Pi dan Arduino Uno
}

\author{
http://dx.doi.org/10.28932/jutisi.v7i1.3421 \\ Riwayat Artikel \\ Received: 19 Februari 2021 | Final Revision: 8 Maret 2021 | Accepted: 29 Maret 2021
}

\author{
Ryan Ganesha Calibra ${ }^{\varpi \# 1}$, Irfan Ardiansah ${ }^{* 2}$, Nurpilihan Bafdal ${ }^{\# 3}$ \\ ${ }^{\#}$ Departemen Teknologi Industri Pertanian, Universitas Padjajaran \\ Jatinangor, Sumedang, Jawa Barat \\ ${ }^{1}$ ryan16003@mail.unpad.ac.id \\ ${ }^{3}$ nurpilihanbafdal@yahoo.com \\ * Departemen Teknologi Industri Pertanian, Universitas Padjajaran \\ Jatinangor, Sumedang, Jawa Barat \\ irfan@gadjah. net
}

\begin{abstract}
Water quality is very important for plant's growth and development. Some of the important part of the water qualities are TDS (Total Dissolved Solid), EC (Electrical Conductivity), pH (Acidity). Cultivation inside a greenhouse provides some benefits but also have some deficiency, such as lack of soil nutrition because most plants inside greenhouse uses non soil growing media. To overcome the deficiency, An automated and remote system is needed to ease the controlling of water quality and nutrition feeding to the plant. This study aims to create low-cost greenhouse water quality monitoring that automatically display the real time data on a website. This research is done by using an engineering design methods. This system can be integrated with auto-pot watering system . The result shows that the system can adjust the TDS and $\mathrm{pH}$ as programmed, which are $T D S=1000-1200$, and $\mathrm{pH}=5.5-6.5$ The TDS sensor in this research have the limitation of reading 0 1200ppm which can not fulfil the plant needs of the nutrition.
\end{abstract}

Keywords - Automation; Internet Of Things; low-cost; Monitoring; Raspberry pi

\section{Pendahuluan}

Air adalah zat yang sangat dibutuhkan bagi semua mahluk hidup untuk bertahan hidup. Peran air sangat penting dan termasuk senyawa yang cukup banyak berada di bumi, menutupi sekitar $70 \%$ dari permukaan bumi. Banyak senyawa yang dapat terlarut di dalam air dan sering disebut dengan pelarut universal. Banyaknya zat yang terlarut didalam air, membuatnya mudah terkontaminasi. Mudahnya kontaminasi terhadap air menyebabkan langkanya air yang benar-benar murni. Karakteristik dan zat yang terkandung dalam air dapat berbeda sedikit dari air murni. Air yang terkandung pada manusia adalah sekitar 55\% hingga 78\%[1]. Potensial air pada tanah mempengaruhi penampungan air dan ketersediaannya, sehingga air memiliki dampek besar bagi pertumbuhan dan produksi pada tanaman. Kandungankandungan di dalam air tanah memberikan pengaruh yang cukup besar pada beberapa karakteristik fisik dan kimia pada tanah. Diantaranya adalah kandungan oksigen, padatan terlarut dan keasaman. Potensial air bergantung pada karakteristik tanah yang berbeda pada setiap waktu dan tempat, tergantung dari keseimbangan antara air dan tanah. Keseimbangan tersebut dipengaruhi oleh input yaitu hujan dan irigasi, serta output yang berupa penguapan, drainase, serta penyerapan oleh tanaman[2].

Karakteristik air tanah dapat berbeda-beda tergantung dari tempat dan waktu[2]. Hal tersebut dibuktikan oleh penelitian yang dilakukan oleh Asmi, Kiki, dan Dian di kecamatan Singkawang. Karakteristik air yang diteliti diantaranya adalah pH dan TDS. Dari tujuh sampel yang diambil dalam satu kecamatan tersebut menghasilkan data bahwa dalam satu kecamatan terdapat perbedaan kualitas air yang signifikan pada tempat yang berbeda. Sampel diambil pada beberapa rumah di kecamatan tersebut. Karakteristik fisika dari ketujuh sampel tersebut memiliki kisaran terrendah $41.9 \mathrm{mg} / \mathrm{l}$ dan tertinggi adalah $1530 \mathrm{mg} / \mathrm{l}$ yang mana nilai tersebut sudah melebihi batas standar mutu. $\mathrm{pH}$ atau tingkat keasaman juga berbeda-beda pada setiap tempat dan tidak bergantung pada TDS dari air tersebut, yaitu berkisar antara 6.4 hingga 7.2 dan masih termasuk pada batas normal [3]. Penelitian tersebut membuktikan bahwa kualitas air pada setiap tempat berbedabeda, tergantung pada lokasi, dekat atau jauh dari irigasi dan 
jarak antar lokasi ke pantai.

Saat ini, penyesuaian kualitas air dengan keperluan tanaman masih dilakukan secara manual. Diperlukan pengawasan secara terus menerus dan dilakukan secara manual. Petani hidroponik masih menggunakan sistem manual akan cukup memakan waktu untuk pemberian nutrisi dan pemantauan harus dilakukan secara langsung di setiap harinya. Untuk pertanian Hidroponik dengan jumlah tanaman yang banyak dan area yang luas juga dapat memakan waktu, dengan cara yang tepat pelaku hidroponik dapat melakukan lebih banyak hal dengan waktu yang sama. Cara yang dapat mempermudah pelaku hidroponik untuk memberikan nutrisi, menyesuaikan $\mathrm{pH}$ dan melakukan pengawasan adalah secara daring melalui perangkat masing-masing sehingga menghemat waktu yang semula digunakan untuk mencampur nutrisi dan melakukan penyesuaian $\mathrm{pH}$. Selain itu, pelaku hidroponik tidak perlu repot untuk memastikan kadar nutrisi (AB mix) tepat untuk tanaman, karena sistem ini akan melakukannya secara otomatis dengan metode on-off dan prinsip titrasi untuk meminimalisir kesalahan pada penambahan nutrisi tersebut.

Penelitian yang akan dilakukan bertujuan untuk membuat sistem yang dapat menyesuaikan kualitas air sesuai dengan kebutuhan tanaman yang akan ditanam dan menerapkan sistem Internet Of Things. Sistem ini akan diprogram untuk melakukan penyesuaian kualitas air sesuai kebutuhan tanaman pada waktu tertentu sesuai dengan jadwal penyiraman autopot. Sistem ini menggunakan Arduino sebagai pembaca data dan untuk melaksanakan otomasi sesuai dengan set point yang telah ditentukan pada program di Arduino tersebut. Data yang dihasilkan kemudian dikirimkan ke raspberry pi melalui serial port sehingga data akan terbaca setiap kali Arduino mengirimkan data. Datadata yang dikirimkan Arduino kepada raspberry pi kemudian akan disimpan di database MySQL, data yang ada di database tersebut yang kemudian akan disajikan melalui HTML dengan menggunakan PHP untuk menunjukkan data dari database ke HTML sehingga bisa dibaca melalui website[4].

Arduino digunakan karena memiliki kemampuan yang baik untuk menangani banyak sensor dan aktuator sekaligus, sehingga tegangan tidak drop dan membuat aktuator tidak dapat berjalan. Arduino pada dasarnya adalah sebuah platform untuk prototyping yang dapat menghasilkan purwarupa hingga tahap desain[5].

\section{TINJAUAN PUSTAKA}

Beberapa penelitian tentang otomasi penyesuaian $\mathrm{pH}$ pernah dilakukan sebelumnya, yaitu penelitian terhadap penyesuaian tingkat keasaman atau $\mathrm{pH}$ dengan menggunakan sensor $\mathrm{pH}$ dan Arduino yang dilakukan oleh Muhammad Tirto Utomo beserta timnya. Prototype yang dibuat menggunakan sensor dan pompa yang memompakan larutan $\mathrm{pH}$ Up dan $\mathrm{pH}$ down untuk menyesuaikan keasaman larutan berdasarkan $\mathrm{pH}$ referensi yang telah diatur pada Arduino. Prototype dapat menyesuaikan tingkat keasaman pada larutan dalam waktu 23 detik dari kondisi $\mathrm{pH} 2.91$ hingga $\mathrm{pH}$ referensi yaitu 6.0-6.5[6]. hal tersebut membuktikan bahwa automasi untuk penyesuaian $\mathrm{pH}$ dapat dilakukan menggunakan Arduino dan sensor $\mathrm{pH}$ untuk Arduino

\section{A. Arduino}

Arduino UNO memiliki keunggulan yaitu memiliki PIN Digital dan Analog karena sudah terdapat ADC (analog to digital converter) sehingga memungkinkan untuk menyambungkan sensor berbasis data analog untuk diproses tanpa perlu menggunakan converter eksternal. Memiliki kemampuan Real time response karena tidak memiliki sistem operasi. Pekerjaan akan dieksekusi satu persatu tanpa menunggu antrian. Arus supply untuk perangkat yang terhubung ke Arduino lebih besar dibandingkan raspberry pi, sehingga memungkinkan pengguna untuk menyambungkan lebih banyak sensor dan aktuator jika menggunakan Arduino[7]. Interfacing dengan sensor-sensor yang ada juga lebih mudah karena banyak sensor yang sudah kompatibel dengan Arduino. Kelemahan dari Arduino terdapat pada penjadwalan sehingga dibutuhkan modul RTC (real time clock) agar penjadwalan dapat dilakukan.

\section{B. Raspberry pi}

Raspberry pi adalah sebuah mikrokomputer yang memiliki ukuran sebesar kartu kredit, atau disebut juga dengan Single Board Computer. Dikembangkan oleh Raspberry pi Foundation, UK, Raspberry pi memiliki standar kemampuan layaknya komputer desktop yang juga memiliki sistem operasi. Raspberry pi juga sudah dilengkapi port USB dan memiliki pin GPIO[8]. Bahasa pemrograman yang digunakan oleh Raspberry pi adalah python dengan sistem operasi yang digunakan adalah Linux[9]

\section{Sensor $p H$}

Sensor pH menggunakan voltase sebagai data analog yang akan dikalkulasikan oleh Arduino. Cara kerja dari sensor ini adalah membaca aktifitas hydrogen dalam satu larutan dengan skala 0-14 (basa kuat hingga asam kuat)[10].

\section{Sensor EC}

Elektrokonduktivitas diukur menggunakan sensor yang prinsip kerjanya adalah memberi tegangan pada elektroda yang terdapat pada ujung probe. Jika probe secara terusmenerus mengeluarkan tegangan satu arah, maka akan terjadi pengendapan pada elektroda sehingga menghambat pengukuran, maka dari itu sensor ini memiliki driver board yang mengubah tegangan satu arah menjadi AC. Setelah tegangan dikeluarkan, salah satu elektroda membaca tegangan yang datang. Pengukurannya mengacu kepada hukum ohm, yaitu konduktasi = arus listrik / tegangan [11]. 


\section{E. Sensor Turbiditas}

Sensor turbiditas berfungsi untuk mendeteksi kekeruhan larutan dengan membaca sifat optik dari larutan tersebut. Cara kerja sensor ini adalah menerima cahaya yang dikirim oleh salah satu elektroda lalu mengukur voltase dari cahaya yang diterima oleh photo diode, semakin tinggi atau rendah tingkat kekeruhan air, voltase output akan ikut berubah[12].

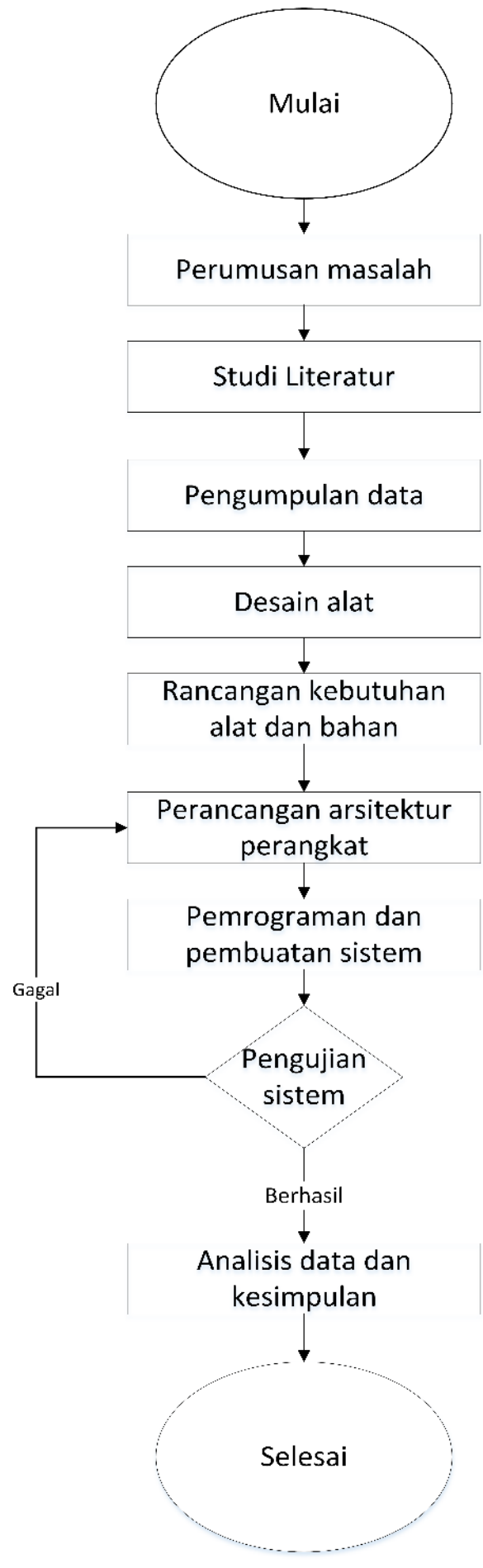

Gambar 1. Tahapan penelitian

\section{F. Sensor suhu}

Sensor suhu DS18B20 adalah sensor digital yang berbasis silikon, kebanyakan sudah mengandung sensor temperatur, analog to digital converter dan memori untuk menyimpan data, sehingga memungkinkan sensor ini melakukan perhitungan dan memberi output data berupa data digital [13].

\section{G. Preferensi penelitian}

Otomasi untuk menyesuaikan tingkat keasaman pernah dilakukan sebelumnya oleh Tirto Utomo dkk. Pada penelitian tersebut Arduino UNO dan sensor $\mathrm{pH}$ yang digunakan berhasil menyesuaikan tingkat keasaman dan ketinggian air sesuai dengan set point yang telah ditentukan. Sensor $\mathrm{pH}$ yang digunakan memiliki ketelitian $\mathrm{pH} \pm 0.2$. sensor ketinggian HC-SR04 memiliki ketelitian $0.26 \mathrm{~cm}$ [6].

Sistem monitoring melalui web pernah dilakukan oleh Zaida dkk. Penelitian ini melibatkan Arduino UNO beserta sensornya untuk melakukan otomasi dan raspberry pi sebagai database server yang menerima data dari Arduino. Penelitian ini membuktikan bahwa Arduino dapat bekerja Bersama dengan Raspberry pi untuk menghasilkan suatu sistem yang terintegrasi antar satu sama lain. Raspberry pi menerima data yang sudah diurutkan lalu dengan Bahasa pemrograman python digunakan untuk array data dari Arduino dan kemudian input data ke database[4].

\section{METODE DAN DESAIN}

Metode yang digunakan pada penelitian ini adalah metode rancang bangun untuk membangun sistem dan membangun prototype.

Dalam merancang otomasi, Bahasa pemrograman C digunakan untuk memprogram Arduino UNO melalui program Arduino IDE yang ada pada laptop atau raspberry pi. Setelah perancangan otomasi pada Arduino UNO selesai, selanjutnya Bahasa pemrograman python dibutuhkan untuk mentranslasikan data yang diterima dari Arduino UNO, mengelompokkannya menjadi variable-variabel tertentu yang dapat dimasukkan ke dalam database yang terdapat pada Raspberry pi. Untuk menyajikan data yang terdapat pada database dalam HTML, digunakan bahasa pemrograman PHP. Pengguna dapat menggunakan VNC untuk mengakses raspberry pi melalui internet untuk mengatur set-point pada Arduino dengan program ArduinoIDE yang terdapat pada Raspberry pi.

\section{A. Tahapan penelitian}

Tahapan-tahapan yang akan dilalui selama penelitian ini berlangsung tergambar pada gambar 1 dan akan dijelaskan sebagai berikut.

1). Identifikasi masalah: Identifikasi masalah dilakukan untuk melihat permasalahan yang ada di tempat penelitian dilakukan. Mencari tahu tentang permasalahan yang berhubungan dengan hidroponik dan pengembangan yang ingin dilakukan. Terhadap masalah tersebut 

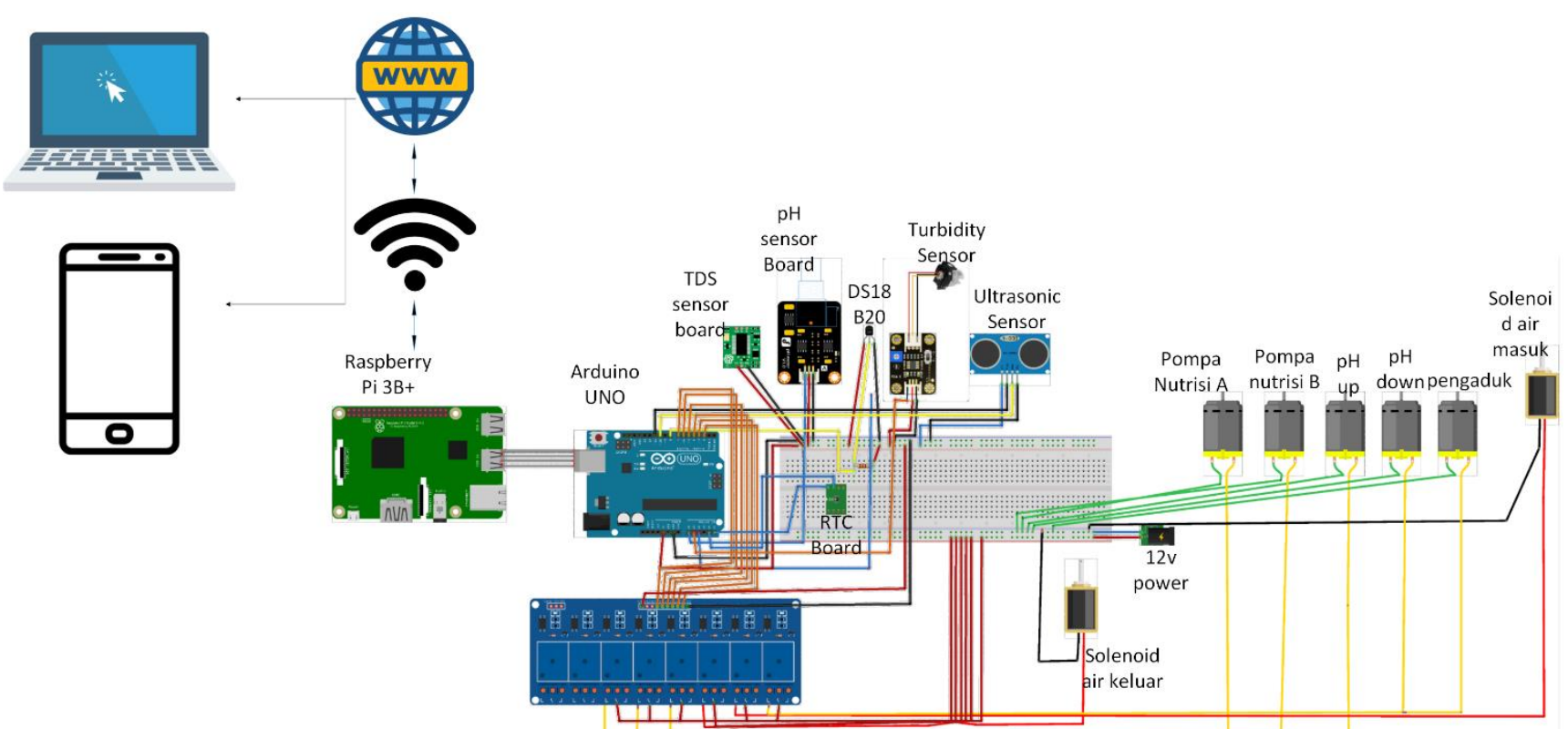

Gambar 2 Skema rangkaian alat

1). Studi Literatur: literatur terhadap penelitian yang sudah pernah dilakukan perlu dikaji untuk mengobservasi penelitian-penelitian serupa yang pernah dilakukan untuk dijadikan referensi serta membuat perbaikan atau melihat alternatif dengan alat serupa dengan harga yang lebih murah

2). Pengumpulan data: Data karakteristik fisika dan kimia tertentu dikumpulkan untuk memberi landasan pada system yang akan dirancang.

3). Rancangan kebutuhan alat dan bahan: Langkah ini dilakukan untuk menganalisis alat dan bahan yang dibutuhkan untuk melakukan penelitian. Alat dan bahan yang dibutuhkan untuk penelitian ini terdapat pada Tabel I

TABEL I

KEBUTUHAN ALAT DAN BAHAN

\begin{tabular}{|l|l|l|l|}
\hline No. & Nama alat & \multicolumn{1}{c|}{ Fungsi } & Jumlah \\
\hline 1 & Arduino UNO & $\begin{array}{l}\text { Kontroler } \\
\text { untuk } \\
\text { melaksanakan } \\
\text { otomasi dan } \\
\text { mengirimkan } \\
\text { data ke } \\
\text { raspberry pi }\end{array}$ & 1 \\
\hline 2 & Breadboard & $\begin{array}{l}\text { Sebagai } \\
\text { terminal untuk } \\
\text { menyambungk } \\
\text { an sensor ke } \\
\text { arduino }\end{array}$ & 1 \\
\hline 3 & DS18B20 & $\begin{array}{l}\text { Mengukur } \\
\text { temperatur air }\end{array}$ & 1 \\
\hline
\end{tabular}

\begin{tabular}{|c|c|c|c|}
\hline No. & Nama alat & Fungsi & Jumlah \\
\hline 4 & $\begin{array}{l}\text { DC DC } \\
\text { converter }\end{array}$ & $\begin{array}{l}\text { Untuk } \\
\text { mensuplai } \\
\text { tegangan } 5 \mathrm{v} \\
\text { untuk relay } \\
\text { dan } 12 \mathrm{v} \text { untuk } \\
\text { motor dc dan } \\
\text { solenoid valve }\end{array}$ & 1 \\
\hline 5 & $\begin{array}{l}\text { DC Peristaltic } \\
\text { pump }\end{array}$ & $\begin{array}{l}\text { Memompa } \\
\text { nutrisi, ph up, } \\
\text { dan ph down } \\
\text { dengan } \\
\text { akurasi yang } \\
\text { cukup baik } \\
\text { dibandingkan } \\
\text { dengan pompa } \\
\text { biasa }\end{array}$ & 1 \\
\hline 6 & Kabel jumper & $\begin{array}{l}\text { Untuk } \\
\text { menyambungk } \\
\text { an sensor dan } \\
\text { actuator ke } \\
\text { Arduino }\end{array}$ & $40 \mathrm{pcs}$ \\
\hline 7 & $\begin{array}{l}\text { Gravity TDS } \\
\text { meter } 1.0\end{array}$ & $\begin{array}{l}\text { Mengukur } \\
\text { TDS dari } \\
\text { suatu larutan }\end{array}$ & 1 \\
\hline 8 & $\begin{array}{l}\text { Motor } \\
\text { pengaduk }\end{array}$ & $\begin{array}{l}\text { Mengaduk } \\
\text { larutan pada } \\
\text { saat } \\
\text { pencampuran }\end{array}$ & 1 \\
\hline 9 & $\mathrm{PH} 4502 \mathrm{C}$ & $\begin{array}{l}\text { Mendeteksi } \\
\text { kadar } \\
\text { keasaman } \\
\text { dalam larutan }\end{array}$ & 1 \\
\hline
\end{tabular}




\begin{tabular}{|c|c|c|c|}
\hline No. & Nama alat & Fungsi & Jumlah \\
\hline 10 & Raspberry pi & $\begin{array}{l}\text { Mengolah } \\
\text { data dari } \\
\text { Arduino dan } \\
\text { menjadi } \\
\text { database } \\
\text { server }\end{array}$ & 1 \\
\hline 11 & Relay & $\begin{array}{l}\text { Sebagai } \\
\text { switch untuk } \\
\text { mengaktifkan } \\
\text { motor dc dan } \\
\text { solenoid valve }\end{array}$ & 1 \\
\hline 6 & Solenoid valve & $\begin{array}{l}\text { Sebagai keran } \\
\text { air masuk dan } \\
\text { keluar yang } \\
\text { dapat diatur } \\
\text { otomatis } \\
\text { melalui } \\
\text { arduino }\end{array}$ & 2 \\
\hline 9 & $\begin{array}{l}\text { Tempat } \\
\text { penampungan } \\
\text { air } 10 \text { liter }\end{array}$ & $\begin{array}{l}\text { Untuk tempat } \\
\text { memproses air }\end{array}$ & 1 \\
\hline 10 & $\begin{array}{l}\text { Turbidity } \\
\text { sensor for } \\
\text { arduino }\end{array}$ & $\begin{array}{l}\text { Mengukur } \\
\text { kekeruhan air }\end{array}$ & 1 \\
\hline
\end{tabular}

4). Perancangan arsitektur perangkat: Alat yang akan dibuat harus didesain agar memiliki workflow yang efektif. Perancangan ini membantu dalam menentukan penempatan alat otomasi dan alat yang bertindak sebagai server untuk meminimalisir terjadinya permasalahan seperti terjatuh atau terkena air. Mekanisme kerja dari alat otomasi yang dibuat adalah seperti gambar 3, dimana terdapat 2 bagian utama yaitu bagian informasi dan teknis. Bagian informasi ditujukan untuk pengguna. Terdiri dari website, database, dan raspberry pi itu sendiri.

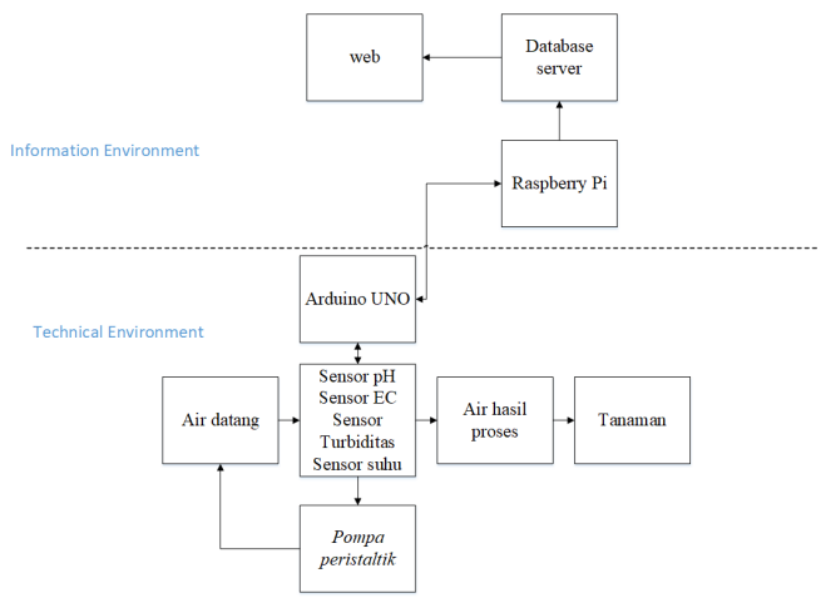

Gambar 3. Desain arsitektur perangkat

\section{5). Rancangan desain}

Desain dari alat yang dirancang pada penelitian ini terdapat pada gambar 2. Arduino memegang peranan penting untuk mengendalikan actuator dan membaca sensor sekaligus menjadi sumber tenaga untuk sensor $\mathrm{pH}$, sensor TDS, sensor turbiditas, sensor suhu, sensor jarak dan Relay sebagai aktuator. Sebelum penelitian ini dilaksanakan, pengujian penyambungan seluruh sensor pada raspberry pi

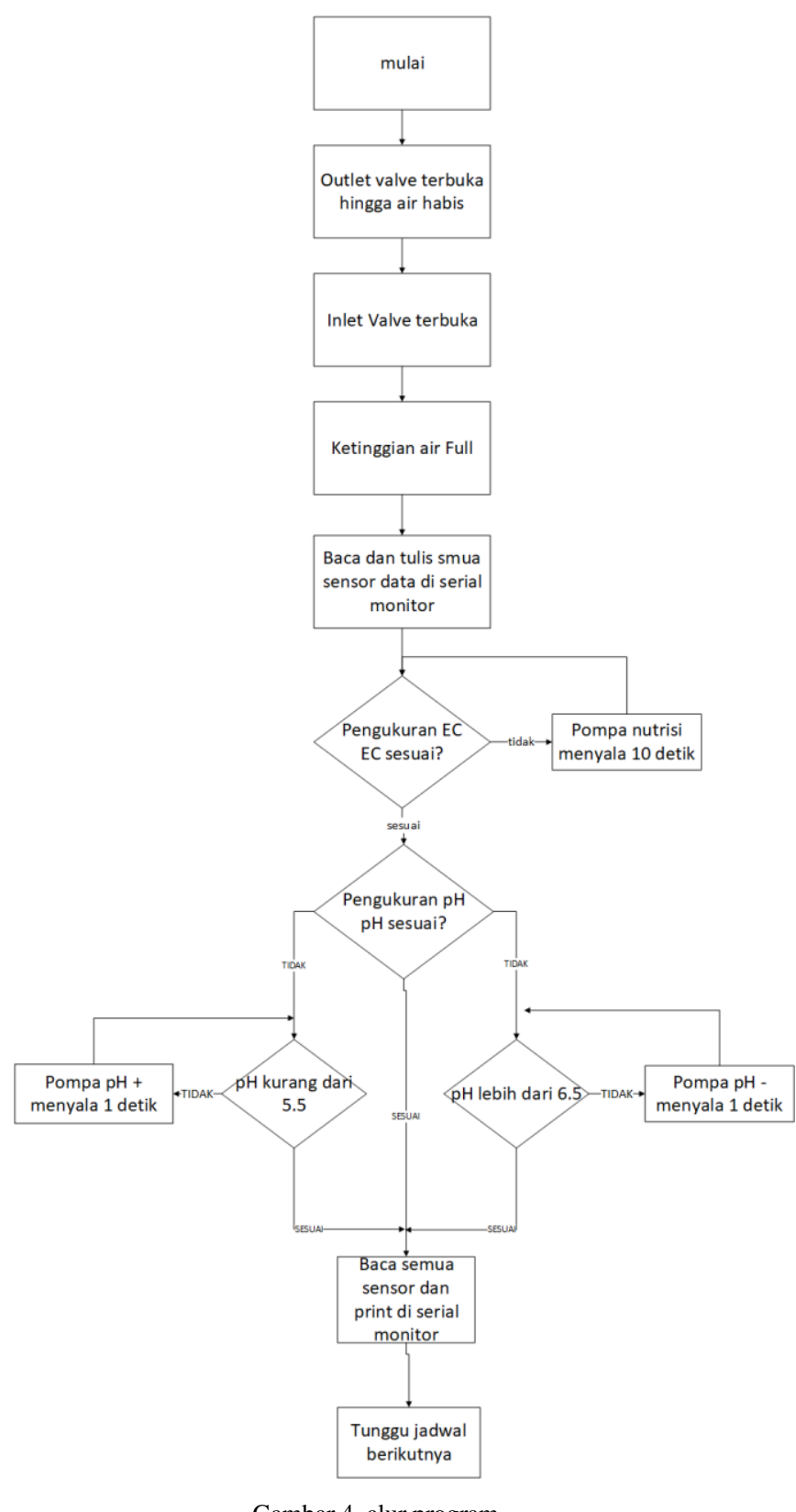

Gambar 4. alur program

sudah dilakukan. Dengan jumlah sensor yang banyak dan relay, sumber tegangan $5 \mathrm{v}$ dari Raspberry pi mengalami drop. relay tidak bisa switching sebagai akibat dari lemahnya tegangan dan kurangnya arus yang dialirkan. Selama penggunaan Arduino, tegangan dan arus lebih stabil. Voltage drop jarang terjadi. Pada pengamatan, melemahnya tegangan supply dapat dilihat dari lampu indikator pada setiap sensor kecuali sensor suhu. Jika lampu tanda menyala pada sensor terlihat lebih redup dari biasanya maka voltage drop terjadi. Hal itulah yang terjadi pada saat percobaan penggunaan 
raspberry pi sebagai mikrokontroler dan mikrokomputer sekaligus.

\section{6). Pemrograman dan pembuatan sistem}

Tahap ini dilakukan dengan mengimplementasikan rancangan-rancangan yang telah dibuat sebelumnya. Pemrograman untuk otomasi pada Arduino dilakukan di Arduino IDE yang tersedia untuk laptop dan juga raspberry pi. Raspberry pi diprogram menggunakan Bahasa python untuk menginterpretasi data yang diterima dari Arduino lalu menjadikan masing masing variable terpisah lalu dimasukkan ke database Skema alur program yang sudah dirancang terdapat pada gambar 4.

Pemrograman yang dilakukan pada Arduino termasuk melakukan kalibrasi menggunakan persamaan linear dan acuan dari datasheet pada sensor. Data yang dikirimkan oleh sensor adalah berupa voltase yang dibaca melalui 10 bit ADC yang menghasilkan nilai 0-1024. Nilai tersebut harus ditranslasikan menjadi data yang sesungguhnya menggunakan persamaan-persamaan garis secara matematis untuk menghasilkan nilai yang tepat.

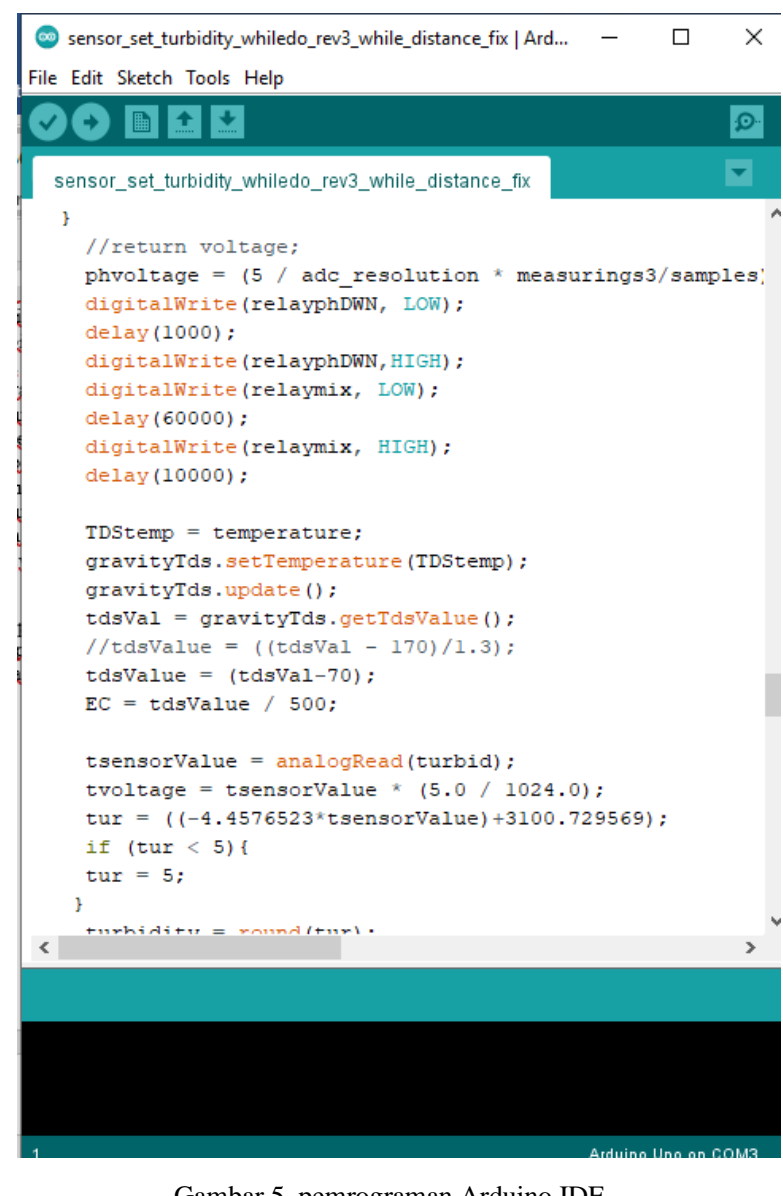

Gambar 5. pemrograman Arduino IDE

Sistem ini dirancang untuk melaksanakan penyesuaian dengan system on-off. Untuk memastikan set point tercapai, pada setiap proses menggunakan while loop sehingga prosesproses yang terjadi dilakukan terus menerus sebelum set point tercapai. Penyesuaian kualitas air oleh sistem menggunakan prinsip yang mirip dengan titrasi. Prinsip titrasi diterapkan dalam sistem karena memiliki beberapa kelebihan diantaranya yaitu konsentrasi nutrisi yang diberikan tidak harus selalu sama, pengguna bisa mengikuti anjuran untuk konsentrat yang tertera pada nutrisi $\mathrm{AB}$ mix atau kurang dari konsentrasi tersebut selama rasio nutrisi A : B tepat. Sistem yang menerapkan perhitungan membutuhkan pembuatan larutan dengan konsentrasi nutrisi yang presisi dan selalu tepat agar perhitungan tidak meleset. Penambahan nutrisi atau penyeimbang $\mathrm{pH}$ dilakukan se sedikit mungkin yang disesuaikan untuk volume 10 liter agar tidak memakan waktu yang terlalu lama. Alur dari program yang dibuat dijelaskan pada gambar 4 .

Pembacaan dari sensor dilakukan saat sebelum menambahkan $\mathrm{pH}$ atau nutrisi, tujuannya agar data yang dihasilkan dapat dianalisis pengaruh dari setiap penambahannya. Jumlah data yang cukup dapat mempermudah proses perhitungan statistik yang akan dilakukan.

Gambar 5 merupakan pemrograman Arduino IDE menggunakan laptop. pada pemrograman ini dilakukan perhitungan voltase dan kalibrasi terhadap sensor. Setiap sensor mempunyai karakteristik yang berbeda sehingga kalibrasi rumus harus dilakukan pada masing-masing sensor. Perbedaan batas nilai Sensor $\mathrm{pH}$, sensor TDS dan turbiditas pada pembacaan ADC menyebabkan persamaan garis berbeda-beda. Batas nilai masing-masing sensor didapatakan dengan memperhitungkan batas nilai masing-masing sensor yang terdapat pada datasheet lalu dihitung menggunakan rumus matematika untuk mencari persamaan linear. Persamaan linear yang tepat akan menghasilkan pembacaan sensor yang tepat.

Data yang dikirimkan oleh Arduino memiliki format sebagai berikut.

\section{Temp:TDS:EC:pH:Turbidity:Proses}

Data yang diterima dari Arduino harus di-decode terlebih dahulu agar bisa dibaca oleh raspberry pi sebagai huruf yang sebenarnya, tanpa decode setiap huruf yang diterima akan dibaca sebagai ASCII. Masing-masing variable dibatasi dengan simbol( : ) yang kemudian dilakukan pemisahan atau Array oleh Raspberry pi untuk memisahkan dan menamakan variable tersebut. Variable yang telah terpisah kemudian dapat didefinisikan Kembali dan dimasukkan ke dalam database pada kolom terpisah. Pemrograman python pada raspberry pi terdapat pada gambar 6 


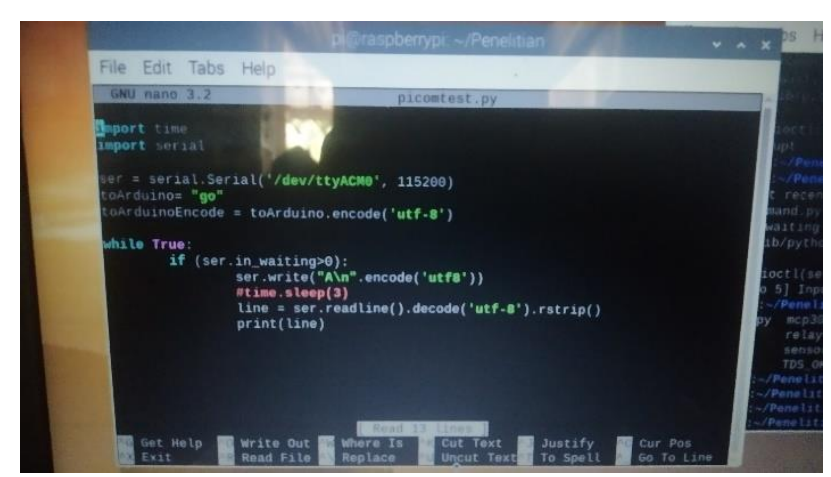

Gambar 6. Pemrograman python pada raspi

5). Pengujian Sistem : Tahap ini dilakukan dengan membuat program Arduino untuk membaca sensor dalam interval beberapa menit. Program yang dibuat dimaksudkan untuk membaca data dan membandingkannya dengan alat ukur pH dan TDS manual(handheld). Pengujian ini dilakukan untuk memastikan range error pada sensor, sehingga saat digunakan di dalam sistem otomasi, sensor sudah diketahui karakteristiknya. Pengujian ini dilakukan dengan penempatan sensor sepetri rancangan, hanya saja belum mengatur kualitas air. Tabel II dan Tabel III menunjukkan data dari pengujian awal ini.

TABEL II

PENGUJIAN SENSOR PH SEBELUM DIGUNAKAN DALAM OTOMASI

\begin{tabular}{|l|l|l|l|l|}
\hline no & pH meter & $\begin{array}{c}\text { Sensor } \\
\text { pH4502C }\end{array}$ & Error & \%error \\
\hline 1 & 7.2 & 7.39 & 0.19 & $2.6 \%$ \\
\hline 2 & 7.1 & 6.85 & 0.25 & $3.5 \%$ \\
\hline 3 & 4.2 & 4.03 & 0.17 & $4.0 \%$ \\
\hline 4 & 4.5 & 4.09 & 0.41 & $9.1 \%$ \\
\hline 5 & 8.1 & 7.84 & 0.26 & $3.2 \%$ \\
\hline 7 & 8.2 & 8.57 & 0.37 & $4.5 \%$ \\
\hline 8 & 8 & 7.93 & 0.07 & $0.9 \%$ \\
\hline 9 & 7 & 7.28 & 0.28 & $4.0 \%$ \\
\hline 10 & 6.7 & 6.42 & 0.28 & $4.2 \%$ \\
\hline & & Rata-rata & 0.25 & $4.0 \%$ \\
\hline
\end{tabular}

Hasil pengujian dari pembacaan sensor terhadap $\mathrm{pH}$ meter pada tabel II menunjukkan ada perbedaan pada hasil. Hal ini disebabkan oleh beberapa faktor. Datasheet yang terdapat pada $\mathrm{pH} 4502 \mathrm{C}$ menyebutkan bahwa toleransi dari sensor ini pada $\mathrm{pH} 7$ adalah hingga \pm 0.5 . pembacaan yang kurang stabil dapat disebabkan karena berada di wadah yang sama dengan sensor TDS yang dapat menyebabkan interfensi arus listrik sehingga mengurangi akurasi pada sensor. Sambungan pada breadboard serta tegangan yang terkadang fluktuatif juga dapat menyebabkan pembacaan $\mathrm{pH}$ dari sensor ini tidak akurat. Permasalahan dari sambungan antara kabel dan pin pada breadboard juga menyebabkan arus dan tegangan listrik yang dihasilkan oleh Arduino tidak sampai dengan maksimal pada papan sirkuit sensor $\mathrm{pH}$ ini.

Sensor $\mathrm{pH}$ yang digunakan juga telah diuji pada beberapa larutan seperti kopi, air jeruk, dan soft drink. Hasil yang didapatkan mendekati nilai asli dari $\mathrm{pH}$ masing-masing larutan berdasarkan data sekunder yang didapatkan dari beberapa sumber terpercaya.

TABEL III

PENGUJIAN SENSOR TDS SEBELUM DIGUNAKAN DALAM OTOMASI

\begin{tabular}{|l|l|l|l|l|}
\hline no & \multicolumn{1}{|c|}{$\begin{array}{c}\text { TDS } \\
\text { meter }\end{array}$} & $\begin{array}{c}\text { Sensor } \\
\text { TDS } \\
\text { Arduino }\end{array}$ & Selisih & \%error \\
\hline 1 & 167 & 172 & 5 & $3.0 \%$ \\
\hline 2 & 256 & 248 & 8 & $3.1 \%$ \\
\hline 3 & 922 & 933 & 11 & $1.2 \%$ \\
\hline 4 & 540 & 532 & 8 & $1.5 \%$ \\
\hline 5 & 1000 & 995 & 5 & $0.5 \%$ \\
\hline 7 & 314 & 321 & 7 & $2.2 \%$ \\
\hline 8 & 16 & 18 & 2 & $12.5 \%$ \\
\hline 9 & 165 & 160 & 5 & $3.0 \%$ \\
\hline 10 & 140 & 135 & 5 & $3.6 \%$ \\
\hline & & $\begin{array}{l}\text { Rata- } \\
\text { rata }\end{array}$ & 6.2 & $3.4 \%$ \\
\hline
\end{tabular}

Hasil pengujian sensor TDS terhadap TDS meter untuk hidroponik (handheld) terdapat pada tabel III. Rata-rata selisih dari keduanya adalah 6.2. Banyak faktor yang menyebabkan pembacaan sensor menjadi kurang tepat. Diantara faktor-faktor tersebut adalah penempatan sensor, aliran air saat pengadukan dan adanya kotoran pada elektroda. Tegangan sumber juga mempengaruhi pembacaan sensor karena setiap sensor memiliki Aref atau tegangan referensi yang berfungsi sebagai referensi untuk kalibrasi nilai maksimum dan minimum yang akan disesuaikan dengan nilai maksimum atau minimum dari sensor untuk mendapatkan nilai yang tepat.

Gravity TDS meter 1.0 adalah sensor TDS untuk Arduino yang digunakan dalam penelitian ini. Sensor ini memiliki rentang nilai pembacaan 0 1200 ppm dengan voltase yang tepat. Tegangan dari sumber 5v Arduino terkadang mengalami fluktuasi yang menyebabkan nilai menjadi tidak akurat. Permasalahan lain selain tegangan sumber adalah sambungan pada breadboard yang terkadang longgar. Longgarnya sambungan pada breadboard menyebabkan arus listrik dan tegangan yang dihasilkan oleh Arduino tidak diterima dengan maksimal oleh papan sirkuit dari sensor ini. Kalibrasi dengan nilai yang tidak tepat dan diluar Batasan yang dimiliki oleh sensor dapat mengakibatkan tidak akuratnya pembacaan dan bahkan dapat terjadi infinite loop 
karena sensor tidak akan dapat mencapai nilai yang ditentukan(diluar range) sehingga loop akan terus berjalan dan penambahan TDS menjadi tidak terkendali. Suhu di sisi lain juga memiliki pengaruh yang tidak signifikan.

\section{IMPLEMENTASI}

Tahap pengujian sensor dan aktuator telah dilakukan. Toleransi aktual dari setiap sensor sudah didapatkan. Alat dan sensor kemudian ditempatkan pada bak pengujian yang didesain lengkap dengan jalur air masuk dan air keluar. Tempat penyimpanan nutrisi serta larutan $\mathrm{pH}$ up dan $\mathrm{pH}$ down disiapkan untuk kemudahan akses dan penempatan yang sesuai untuk pompa peristaltic untuk memompa larutan.

Sistem dijalankan selama satu bulan. Air akan masuk dan keluar setiap 6 jam sekali untuk mengikuti penjadwalan penyiraman tanaman dengan sistem autopot. Pada saat sistem running, data akan dikirimkan setiap proses sedang terjadi, ada 5 proses atau titik pembacaan data yaitu saat air masuk, proses penaikkan TDS dan EC, penaikan $\mathrm{pH}$, penurunan $\mathrm{pH}$, dan pada saat semua loop selesai dilakukan, yaitu Ketika semua variable sudah sesuai dengan set point . Jumlah masing-masing loop akan berbeda-beda tergantung dari kualitas air yang datang.

\section{A. Algoritma Otomasi}

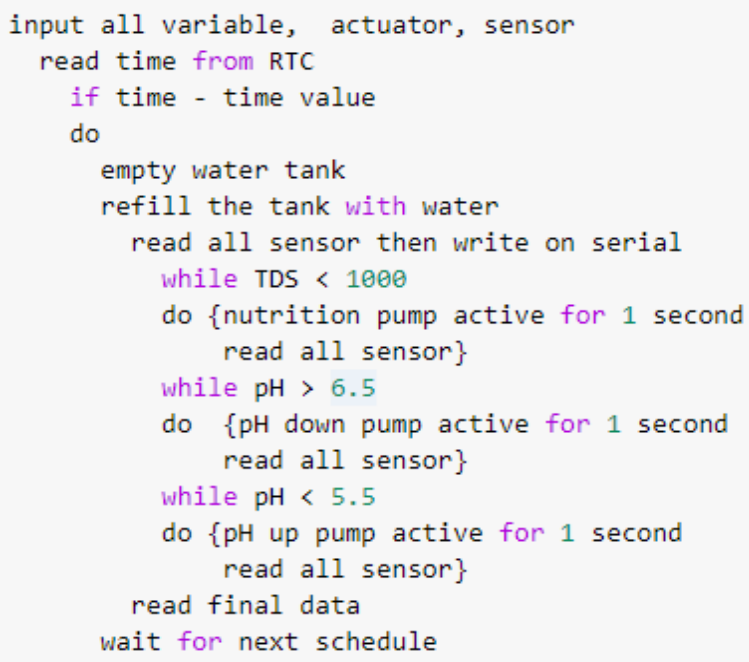

Gambar 7. Logika program pada arduino

Gambar 7 menjelaskan tentang algoritma yang dijalankan oleh Arduino. Arduino akan menjalankan program dengan jadwal tertentu. Pada penelitian ini jadwal yang digunakan adalah setiap 6 jam per hari untuk pengujian.

Arduino membaca data dari sensor setiap while loop dijalankan. Dengan pebacaan dari setiap while loop, data penyesuaian masig-masing parameter akan didapatkan dengan perbandingan waktu. While loop akan berhenti lalu masuk ke tahap berikutnya setelah kondisi tidak sesuai, sebagai contoh jika nilai TDS 1001, maka kondisi while loop untuk tds menjadi salah karena nilai TDS > 1000. While loop untuk penyesuaian TDS berhenti lalu masuk ke tahap berikutnya yaitu penyesuaian $\mathrm{pH}$.jika kondisi ph $5.5<\mathrm{pH}<6.5$ maka loop penyesuaian $\mathrm{pH}$ tidak akan dijalankan. Akan tetapi jika nilai pH kurang dari 5.5 atau lebih dari 6.5 maka loop penyesuaian $\mathrm{pH}$ akan dijalankan untuk menyesuaikan $\mathrm{pH}$. Cuplikan program pada gambar 7 adalah algoritma dan alur jalannya program.

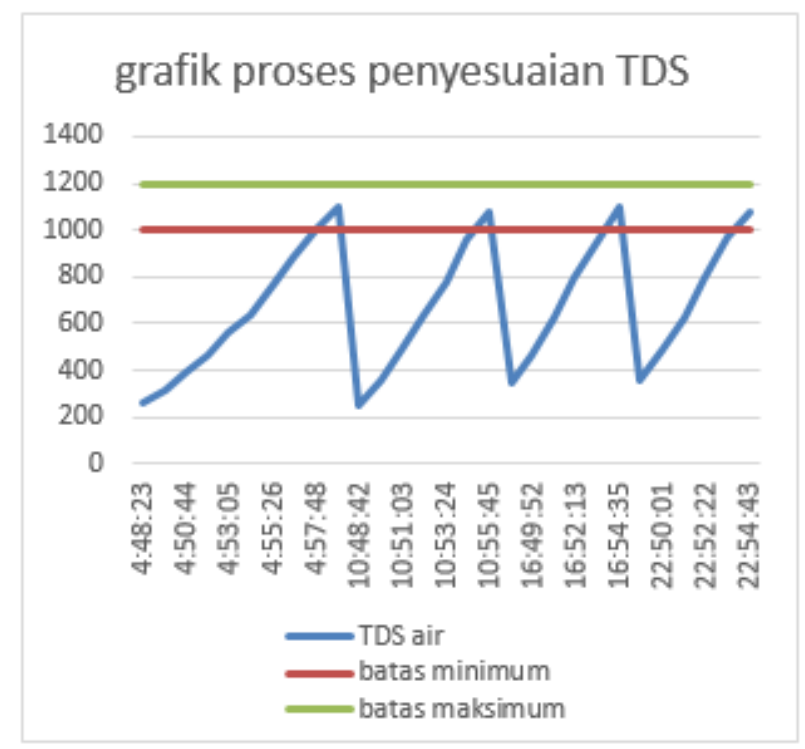

Gambar 8. Grafik TDS pada proses dalam 1 hari

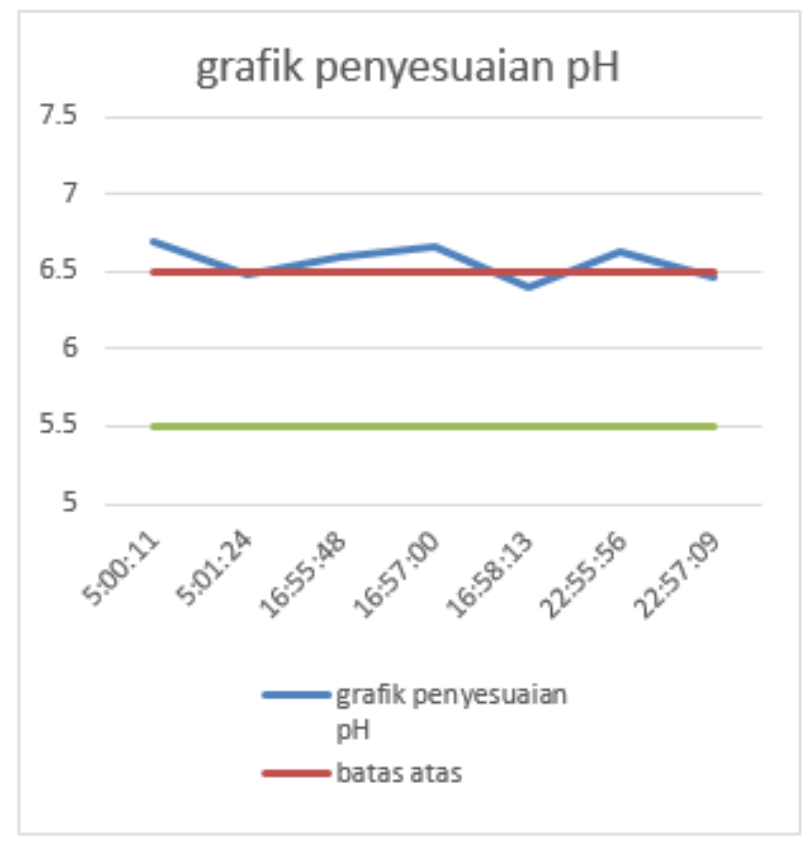

Gambar 9. proses penyesuaian $\mathrm{pH}$ selama 1 hari

B. Analisis sistem

Data TDS air datang dianalisis saat sistem menerima air masuk, pada sistem ini dibuat jadwal air masuk setiap 6 jam sekali yaitu pada jam 4:30, 10:30, 16:30, dan jam 22:30. Air yang masuk dianalisis terlebih dahulu lalu dikirim melalui 
serial port. Data yang masuk pada database tidak akan tepat pada waktu-waktu tersebut dikarenakan sebelum mulai membaca sensor, air yang sudah diproses sebelumnya akan dikeluarkan lalu kemudian air untuk proses selanjutnya akan masuk. Proses air untuk keluar dari tangki dan masuknya air ke tangki proses membutuhkan waktu kurang lebih 5 menit.

Proses pertama terjadi pada jam 04:30. Pada saat tersebut air di penampungan dikosongkan lalu air untuk proses saat itu masuk dengan nilai TDS yang rendah. Pada pukul 4:48 pembacaan data TDS air masuk dilakukan dan didapatkan nilai TDS air tersebut yaitu 261. Proses penambahan nutrisi $\mathrm{AB}$ mix dilakukan dengan menyalakan pompa nutrisi A dan B. Pompa tersebut menyala dan proses terjadi akibat nilai TDS yang belum sesuai dengan Set point yang ditetapkan. Nilai TDS pada awal proses terjadi penambahan pada proses berikutnya yang disebabkan adanya sedikit sisa air dari proses sebelumnya yang mengandung nutrisi dan nilai TDS yang tinggi. Pada proses-proses berikutnya nilai TDS pada awal proses akan stabil. Pada gambar 8, dapat dilihat bahwa alat ini dapat menyesuaikan nilai TDS sesuai dengan set point. Penambahan Nutrisi berhenti pada saat TDS mencapai batas nilai 1000. Proses penyesuaian TDS pada setiap prosesnya terjadi selama 5 hingga 10 menit. Semakin dekat TDS air datang dengan batas yang telah ditentukan, maka akan semakin singkat proses yang terjadi.

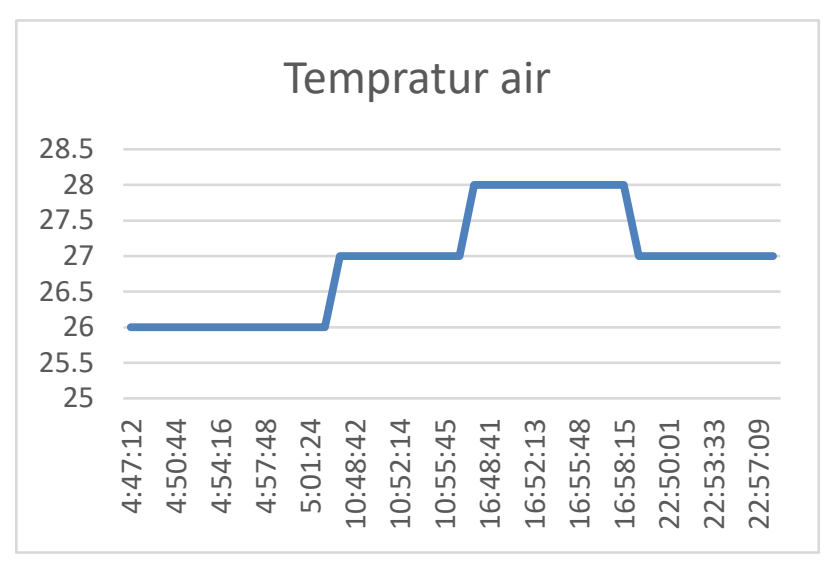

Gambar 10. Grafik temperatur selama 1 hari

TDS yang telah sesuai dengan standar yang ditentukan kemudian akan disesuaikan kadar keasamannya dengan menggunakan sensor PH4502C. jika kadar keasaman dari proses sebelumnya sudah sesuai, maka proses penaikan atau penuunan $\mathrm{pH}$ tidak dilakukan. Penurunan atau penaikan $\mathrm{pH}$ dilakukan oleh aktuator berupa motor DC melalui relay yang akan menyala selama 1 detik pada setiap prosesnya sebelum pH sesuai dengan batas yang telah ditentukan.

Sistem berhasil menyesuaikan $\mathrm{pH}$ hingga mencapai batas pH 6.5 kemudian berhenti menurunkan $\mathrm{pH}$ setelah tercapai. Proses penyesuaian $\mathrm{pH}$ ini sangat bergantung pada akurasi sensor, jika sensor mengalami error dan nilai menjadi lebih dari 6.5 maka proses penurunan $\mathrm{pH}$ akan bertambah. Pada keadaan normal, penurunan $\mathrm{pH}$ pada setiap prosesnya dapat menurunkan nilai $\mathrm{pH}$ sebesar 0.16 .
Sensor $\mathrm{pH}$ yang digunakan pada penelitian ini merupakan sensor dengan harga yang murah dibandingkan dengan sensor pH lainnya. Sensor ini sangat rentan terhadap gangguan seperti aliran air, probe sensor lain yang berada dalam satu wadah dan posisi penggunaan sensor.

Dalam menjalankan sistem, sensor $\mathrm{pH}$ harus ditempatkan sedemikian rupa sehingga menjadi yang pertama kontak dengan air pada setiap proses pengisian. Jika sensor ini letaknya sedikit lebih tinggi dari sensor TDS sehingga sensor TDS lebih dulu melakukan kontak terhadap air, nilai pH yang dihasilkan akan meleset jauh dan alat harus direstart sampai nilai pH kembali seperti kalibrasi sebelumnya. BNC connector untuk Probe sensor ini juga sangat mudah terganggu. Jika circuit board dari sensor ini tergeser, akan ada potensi sensor akan error. Sensor ini kurang stabil. Dapat dilihat pada contoh yang terdapat pada gambar 9, dimana pada proses ketiga pada hari tersebut proses penurunan yang dilakukan pada pukul 16:55 mengalami kenaikan pada pembacaan berikutnya pada pukul 16:57. Kenaikan nilai tersebut sebesar 0.05 yang seharusnya mengalami penurunan karena larutan $\mathrm{pH}$ down telah dialirkan ke dalam tangki pada proses penurunan $\mathrm{pH}$ pertama.

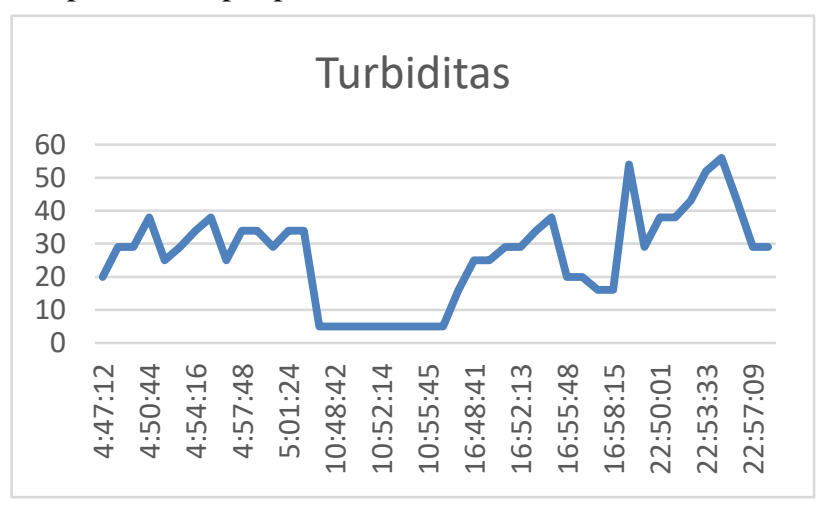

Gambar 11. Grafik nilai turbiditas selama 1 hari

Data pendukung pada penelitian ini adalah kekeruhan air dan temperatur air yang dibaca oleh sensor. Pada sumbersumber seperti website Arduino dan Github sensor suhu DS18B20 memiliki library yang mempermudah penggunanya untuk memprogram Arduino mengenali dan membaca sensor tersebut. Library yang digunakan adalah OneWire. Data yang dihasilkan dari sensor ini adalah bilangan desimal, akan tetapi pada penelitian ini nilai temperatur yang dihasilkan merupakan bilangan bulat. Grafik pada gambar 10 menunjukkan perbedaan suhu pada waktu yang berbeda. Suhu air cenderung lebih rendah pada pagi hari dan malam hari. Cuaca yang cerah pada siang dan sore hari menyebabkan pemanasan pada tempat penampungan air 
sehingga suhu air mengalami kenaikan pada saat dialirkan ke tangki proses. Pada saat proses penyesuaian kualitas air terjadi, suhu tidak mengalami kenaikan ataupun penurunan. Tidak terjadinya kenaikan atau turunnya suhu disebabkan karena pencampuran yang terjadi tidak membuat larutan menjadi pekat atau konsentrat.

Turbiditas atau nilai kekeruhan air yang diproses tertera pada gambar 11. Data yang dihasilkan menunjukkan bahwa terjadi fluktuasi dari rentang nilai 5 hingga 57. Range kekeruhan yang dpat dibaca oleh sensor ini adalah 0-3000 dengan nilai 0 NTU adalah aquadest atau air murni tanpa kontaminan, serta termasuk dalam kategori sangat jernih. Nilai Turbiditas 3000 NTU adalah keadaan dimana cahaya tidak bisa tembus sama sekali ketika dipancarkan sinar oleh salah satu probe. Sensor ini memiliki kelemahan yaitu dapat terjadi bias dalam pembacaannya yang diakibatkan oleh cahaya dari lingkungan. Jika cuaca sangat terik, maka nilai turbiditas akan turun. Hal tersebut dikarenakan Photo diode menerima cahaya tambahan selain dari pemancar yang terdapat pada sensor tersebut.

Beberapa hal dapat dilakukan untuk mengurangi bias dari pembacaan sensor ini, diantaranya adalah dibuat penutup untuk sensor turbiditas agar dapat terhndar dari cahaya matahari. Penempatan alat secara keseluruhan agar terhindar dari paparan cahaya matahari. Penempatan alat secara keseluruhan agar terhindar dari cahaya matahari juga mengikuti anjuran untuk penyimpanan nutrisi $\mathrm{AB}$ mix dan larutan pH. Penyimpanan larutan yang tepat dapat menghindari terjadinya reaksi kimia yang dapat merusak larutan itu sendiri.

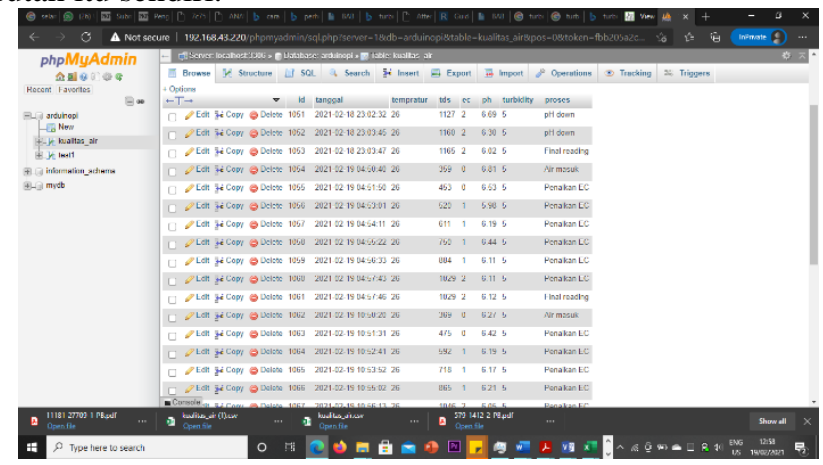

Gambar 12. Database yang dihasilkan

Keberhasilan transfer data dari Arduino menuju raspberry pi dan database adalah $100 \%$. Data yang dihasilkan oleh Arduino selalu berhasil dimasukkan ke dalam database. Jumlah data yang ada pada database berdasarkan jumlah proses yang dilakukan. Program python akan menunjukkan error apabila data tidak berhasil diupload ke dalam database dan jika dalam prosesnya berhasil, maka pada terminal akan tertulis nilai-nilai dari setiap variable dan kata "sukses" yang mengindikasikan keberhasilan pengiriman data ke dalam database.

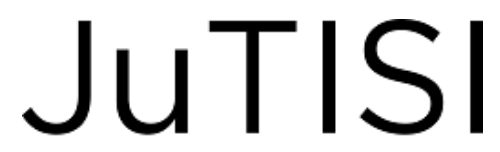

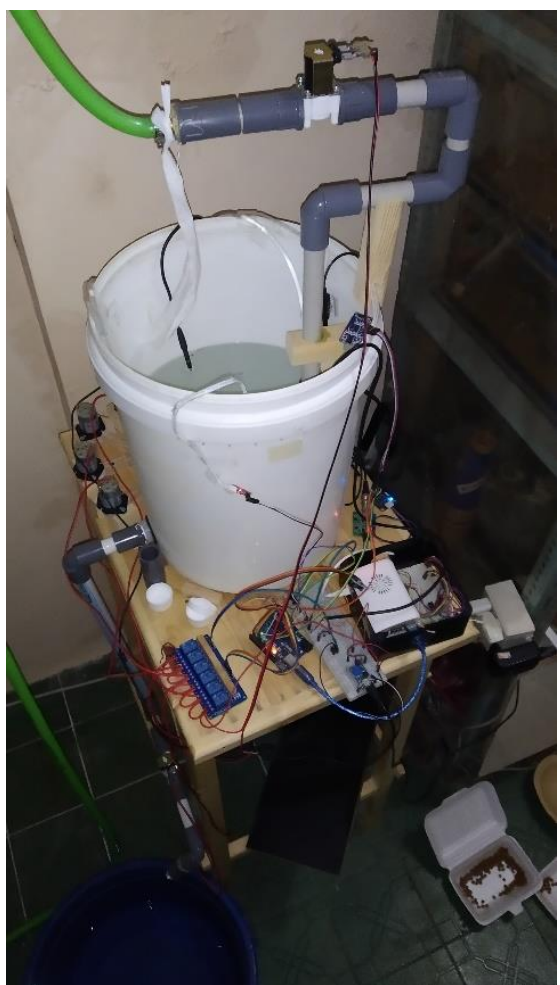

Gambar 13. Prototype

Prototype yang telah dibuat ditunjukkan pada gambar 13. Pipa pada bagian atas adalah jalur untuk air masuk. Pada bagian dasar tempat tangka air diletakkan seluruh peralatan termasuk pompa peristaltik, nutrisi $\mathrm{AB}$ mix dan larutan $\mathrm{pH}$ pada bagian belakang. Solenoid valve yang terletak pada posisi outlet diletakkan jauh lebih rendah dari tangki proses agar pada saat larutan harus dikeluarkan dari tangka proses terdapat tekanan yang membantu mempercepat arus air yang keluar.

Penempatan sensor didesain untuk mempermudah instalasi dan untuk mendapatkan data yang akurat sensorsensor diletakkan pada posisi permukaan air. Jika sensor diletakkan pada bagian bawah tangka, ada kemungkinan terjadi kebocoran seal yang menyebabkan air tumpah ke bagian dasar dan membasahi mikrokontroler dan mikrokomputer. Sensor Turbiditas memiliki bagian atas yang terbuka. Hal tersebut dapat menimbuklan kerusakan apabila air masuk ke dalamnya. Sensor $\mathrm{pH}$ memiliki batas bagian yang boleh tenggelam, jika melebihi batas tersebut, ada kemungkinan terjadinya korsleting atau hubungan arus pendek yang menyebabkan kerusakan pada sistem kelistrikan pada probe sensor tersebut maupun pada papan sirkuit atau scenario terburuk dapat merusak pin 5V pada Arduino. Probe dari sensor TDS yang digunakan adalah waterproof sehingga probe ini aman apabila harus dalam posisi submerged. Pada penempatannya, sensor TDS ini direkomendasikan agar tidak menempel pada dinding penampang untuk mendapatkan data yang akurat. Sensor suhu DS18B20 yang digunakan dalam penelitian ini adalah sensor yang sudah dikemas dalam tempat stainless steel dan penutup untuk kabel sehingga 
sensor ini temasuk sensor yang tahan terhadap air. Sensor ini juga tidak memicu ground loop dan tidak berpengaruh pada sensor lain yang berada dalam satu wadah yang sama.

\section{KESIMPULAN}

Sistem yang dibuat pada penelitian ini berhasil menyesuaikan kadar TDS dan $\mathrm{pH}$ sesuai ketentuan yang telah dibuat. Sensor $\mathrm{pH} 4502 \mathrm{C}$ bisa digunakan untuk sistem otomasi untuk biaya yang cukup murah, akan tetapi sensor tersebut mengalami fluktuasi paling besar pada nilai 0.41 . nilai tersebut masih berada di dalam batas toleransi yang tertera pada datasheet sensor tersebut. Nilai TDS dari air yang datang berhasil disesuaikan oleh sistem ini, saat nilai TDS mencapai 1000, sistem berhenti menambahkan larutan nutrisi pada bak penampungan. Nilai TDS yang tebaca oleh sensor dan nilai aktual memiliki selisih rata-rata 6.2 berdasarkan pengujian yang telah dilakukan. Pengadukan menggunakan magnetic stirrer tidak memicu ground loop dan tidak mengganggu sensor. Sistem dapat diatur menggunakan VNC untuk mengakses raspberry pi melalui jaringan internet.

\section{DAFTAR PUSTAKA}

[1] M. Z. Hossain, "Water : The Most Precious Resource Of Our Life," no. October, 2015.

[2] G. Chavarria and H. Pessoa, "Plant Water Relations: Absorption,
Transport and Control Mechanisms," no. May 2014, 2012.

[3] M. Storet and S. Utara, "Analisis Dan Identifikasi Status Mutu Air Tanah Di Kota Singkawang Studi," no. 82, pp. 1-10, 2016.

[4] Zaida, I. Ardiansah, and M. A. Rizky, "Rancang Bangun Alat Pengendali Suhu Dan Kelembaban Relatif Pada Rumah Kaca Dengan Informasi Berbasis Web," J. Teknotan, vol. 11, no. 1, 2017.

[5] H. W. Saptaji, "Mudah belajar Mikrokontroller dengan Arduino," Bandung: Widya Media, 2015.

[6] M. T. Utomo, V. Vekky, R. Repi, and F. Hidayanti, "Pengatur Kadar Asam Nutrisi ( $\mathrm{pH}$ ) dan Level Ketinggian Air Nutrisi pada Sistem Hidroponik Cabai,” vol. 21, no. 1, pp. 5-14, 2018.

[7] I. Ardiansah et al., "Perbandingan Analisis SWOT Antara Platform Arduino UNO dan Raspberry Pi," pp. 27-28, 2016.

[8] A. Nayyar and V. Puri, "Raspberry Pi-A Small, Powerful, Cost Effective and Efficient Form Factor International Journal of Advanced Research in Raspberry Pi- A Small , Powerful , Cost Effective and Efficient Form Factor Computer : A Review," no. July, 2016.

[9] A. Kurniawan, "Introduction to Raspberry Pi," pp. 1-25, 2019.

[10] Reshma, P. Bangera, Chethana, K. Nadig, and Keerthi, "Raspberry Pi based Soil Parameters Monitoring," no. May, 2018.

[11] D. Li and S. Liu, "Sensors in Water Quality Monitoring," 2019, pp. $1-54$

[12] R. A. Wadu, Y. S. B. Ada, and I. U. Panggalo, "Rancang Bangun Sistem Sirkulasi Air Pada Akuarium / Bak Ikan Air Tawar Berdasarkan Kekeruhan Air Secara Otomatis," pp. 1-10, 2017.

[13] CircuitBasics, "Raspberry Pi DS18B20 Temperature Sensor Tutorial," $2016 . \quad$ [Online]. Available https://www.circuitbasics.com/raspberry-pi-ds18b20-temperaturesensor-tutorial/. 